\title{
SKOPOLETIN SUATU SENYAWA FENILPROPANOID DARI EKSTRAK ETIL ASETAT UMBI UBI JALAR (Ipomoea batatas L.)
}

\author{
Choirotul Isma, Nanik Siti Aminah* dan Alfinda Novi Kristanti ${ }^{1}$ \\ ${ }^{1}$ Prodi S-1 Kimia, Departemen Kimia, Fakultas Sains dan Teknologi, \\ Universitas Airlangga, Surabaya \\ *email: nanik-s-a@ fst.unair.ac.id
}

Received 20 October 2018

Accepted 20 December 2018

\begin{abstract}
Abstrak
Telah berhasil diisolasi senyawa golongan fenil propanoid dengan nama "skopoletin" dari ekstrak etil asetat umbi Ubi Jalar (Ipomoea batatas L.). Ekstraksi senyawa fenolik dilakukan dengan metode maserasi menggunakan pelarut metanol, dilanjutkan partisi menggunakan nheksana dan etilasetat. Pemurnian dilakukan dengan kromatografi kolom gravitasi dan ktomatografi radial menghasilkan senyawa golongan fenil propanoid. Struktur skopoletin diidentifikasi berdasarkan data spektrum UV, 1D dan 2D NMR.
\end{abstract}

Kata kunci : fenil propanoid, skopoletin, dan Ipomoea batatas $L$.

\begin{abstract}
Phenylpropanoid group compound has been isolated as "scopoletin" from ethylacetate extract of tuber flesh Sweet potatoes (Ipomoea batatas L.). Extraction of phenolic compound was done by maceration method using methanol solvent, then partition with n-hexana and ethylacetate, respectively. The process of purification using various chromatographic techniques yielded compound of phenylpropanoid group. Structure of scopoletin is identified based on UV, 1D, and 2D NMR spectra.
\end{abstract}

Keyword : phenyl propanoid, scopoletin, dan Ipomoea batatas L.

\section{Pendahuluan}

Ubi jalar dengan nama latin Ipomoea batatas L. merupakan tanaman yang mengandung senyawa metabolit sekunder dan memiliki banyak manfaat, salah satunya adalah golongan fenolik ubi jalar adalah golongan senyawa fenolik. Senyawa fenolik yang terdapat pada ubi jalar misalnya senyawa- senyawa golongan fenil propanoid, flavonoid, dan lignan. (Meira et $a l, 2014)$. ). Senyawa fenilpropanoid yang sering ditemukan yaitu turunan asam sinamat dan kumarin. Sedangkan senyawa golongan flavonoid yang sering ditemukan yaitu golongan antosianin, jadi masih ada peluang cukup besar untuk diteliti lebih lanjut. Ubi jalar (Ipomoea batatas L.) mempunyai enam varietas unggul pada daerah Malang, Jawa Timur anata lain, ubi IR melati, ubi ungu, ubi Gunung Kawi, ubi Sari, ubi Mr. Ong, dan ubi Steven. Pada penelitian ini menggunakan ubi jalar IR karena merupakan varietas yang banyak terdapat di daerah Malang (Ariadi, 2006). Penelitian ini bertujuan untuk mengisolasi senyawa fenolik dari umbi ubi jalar putih (Ipomoea batatas L.). Umbi ubi jalar merupakan bagian umbi yang sudah dikupas 
dan diperkecil hingga membentuk serbuk kasar. Tahap pertama untuk isolasi dari senyawa fenolik pada umbi ubi jalar (Ipomoea batatas L.) meliputi ekstraksi dengan cara maserasi menggunakan metanol untuk mendapatkan ekstrak. Ekstrak metanol ubi jalar dipartisi dengan $n$-heksana dan etil asetat. Umbi ubi jalar yang terdapat pada fraksi etil asetat kemudian dipisahkan masing-masing senyawa dengan menggunakan berbagai teknik kromatografi. Penentuan struktur senyawa hasil isolasi dilakukan dengan metode spektroskopi yang meliputi: spektrofotometer UV-Vis dan NMR. Uji aktivitas antioksidan menggunakan ekstrak etil asetat umbi ubi jalar karena jumlah senyawa yang berhasil diisolasi sedikit.

\section{Metode Penelitian}

\section{Umum}

Kromatografi kolom gravitasi menggunakan Si-gel G60, kromatografi radial menggunakan Si-gel $60 \mathrm{PF}_{254}$, dan analisis KLT menggunakan plat KLT Kieselgel $60 \mathrm{GF}_{254} 0.25 \mathrm{~mm}$. Spektrum UV ditetapkan dengan spektrometer Shimadzu UV-1800, spektrum ${ }^{1} \mathrm{H}-\mathrm{NMR}$ dan ${ }^{13} \mathrm{C}-\mathrm{NMR}$ ditentukan dengan spektrometer BRUKER yang beroperasi pada $600 \mathrm{MHz}\left({ }^{1} \mathrm{H}\right)$ dan 150 $\mathrm{MHz}\left({ }^{13} \mathrm{C}\right)$ menggunakan pelarut DMSO. Penentuan sifat antioksidan menggunakan uji DPPH dengan menghitung nilai $\mathrm{IC}_{50}$.

\section{Bahan Tanaman}

Bahan tumbuhan yaitu Bahan tanaman yang diteliti adalah ubi jalar (Ipomoea batatas L.) merupakan varietas IR-Melati yang diperoleh dari Desa Pamotan, Kecamatan Dampit, Kabupaten Malang, Jawa Timur.

\section{Ekstraksi dan isolasi.}

Serbuk umbi ubi jalar (3,5 kg) diekstraksi dengan metode maserasi menggunakan metanol sebanyak dua kali. Ekstrak metanol yang diperoleh dipekatkan dengan alat penguap bertekanan rendah sehingga diperoleh ekstrak kental metanol. Ekstrak metanol selanjutnya dipartisi dengan nheksan dan etil asetat. Ekstrak etil asetat (6,8 g) dipisahkan dengan kromatografi kolom gravitasi dengan campuran eluen n-heksana : etil asetat (10\% sampai 100\%) menghasilkan lima fraksi utama A,B, C, D, dan E. Pemisahan fraksi $\mathrm{D}$ dengan kromatografi radial (eluen campuran $n$ heksana:etil asetat $=8: 2$ ) menghasilkan lima subfraksi D1, D2, D3, D4, dan D5. Pemurnian subfraksi D2 dengan kromatografi radial (eluen $n$-heksana : etil asetat $=7: 3$ ) diperoleh senyawa golongan fenilpropanoid (3,3 mg) yaitu skopoletin. Penentuan struktur skopoletin dilakukan dengan analisis dpektrum UV, 1D dan 2D NMR.

\section{Hasil dan Pembahasan}

Skopoletin merupakan senyawa golongan fenilpropanoid yang berbentuk padatan kuning pucat memiliki massa 3,3 mg. Analisis KLT menggunakan tiga sistem eluen dari senyawa 1 menggunakan eluen nheksana:etil asetat (6:4), aseton:etil asetat (9:1), n-heksana:etil asetat (7:3) menunjukkan noda tunggal dengan Rf untuk masing-masing eluen yaitu; 0,43, 0,40, dan 0.32 .

Skopoletin, spektrum UV (MeOH) $\lambda$ maks $\mathrm{nm}(\log \varepsilon): 388,50(4,38)$ dan 229,00 $(4,58)$. Data spektrum ${ }^{1} \mathrm{H}$ NMR dan ${ }^{13} \mathrm{C}-\mathrm{NMR}$ (Aseton) $600 \mathrm{MHz}: \mathrm{H} 3$ 6,15; H4 7,82; H5 7,16; H8 6,77; 6-OMe 3,88; C2 161,3; C3 113,2; C4 144,6; C5 110,0; C6 146,0; C7 151,9; C8 103, 7; C8a 151,1; C8b 112,0; 6OMe 56,7.

Analisis Spektrofotometer UV-Vis dari senyawa skopoletin dilakukan dengan melarutkan $0.1 \mathrm{mg}$ sampel dalam $5 \mathrm{ml}$ metanol. Hasil spektrum UV menunjukkan panjang gelombang maksimum (log $\varepsilon$ ) untuk senyawa skopoletin adalah $388,50(4,38)$ $\mathrm{nm}$ dan 229,0 $(4,58) \mathrm{nm}$ yang karakteristik untuk senyawa kumarin dan turunannya 
(Scott, A. I., 1964). Pengukuran dengan penambahan pereaksi geser $\mathrm{NaOH}$ dilakukan untuk mengetahui adanya gugus hidroksi yang terikat pada benzena (Harbone, 1984). Nilai panjang gelombang ( $\log \varepsilon$ ) spektrum UV dengan penambahan pereaksi geser $\mathrm{NaOH}$ adalah $346,0(3,95)$ nm dan 297,0 (3,64).

Spektrum ${ }^{1} \mathrm{H}-\mathrm{NMR}$ senyawa skopoletin dalam Aseton memperlihatkan dua sinyal doublet $(\mathrm{J}=9,5) \delta_{\mathrm{H}} 6,15 \mathrm{ppm}$ dan $\delta_{\mathrm{H}} 7,82$ ppm merupakan proton olefinik dengan geometri cis. Dua sinyal singlet pada daerah aromatik $\delta_{\mathrm{H}} 6,77 \mathrm{ppm}$ dan $\delta_{\mathrm{H}} 7,16 \mathrm{ppm}$ menunjukkan proton aromatik yang terletak pada posisi para. Sinyal singlet $\delta_{\mathrm{H}} 3,88 \mathrm{ppm}$ muncul pada daerah hidroksi yang merupakan sinyal subtituen metoksi .

Analisis spektrum ${ }^{13} \mathrm{C}$-NMR muncul sinyal karbon kuartener pada pergeseran kimia $\left(\delta_{\mathrm{c}} 112,0 ; 146,0 ; 151,1 ; 151,9\right.$ dan $161,3 \mathrm{ppm})$, Sinyal karbon metin pada pergeseran kimia $\left(\delta_{\mathrm{c}} 103,7 ; 110,0 ; 113,2\right.$; dan 144,6 ppm), dan sinyal karbon metoksi pada daerah $\delta_{\mathrm{c}} 56,7 \mathrm{ppm}$. Proton aromatik dengan pergeseran $\left(\delta_{\mathrm{H}} 6,77 \mathrm{ppm}, \mathrm{s}\right)$ pada $\mathrm{C} 8$ berkorelasi dengan sinyal karbon kuartener ( $\delta_{\mathrm{C}} 112,0 ; 151,1 ; 151,9 ;$ dan 146,0 ppm). Berdasarkan ${ }^{1} \mathrm{H}$ dan ${ }^{13} \mathrm{C}$ NMR dari senyawa 1 diprediksi bahwa struktur kerangka dasar senyawa 1 adalah kumarin.

Analisis HSQC menunjukkan lima kontur yang menggambarkan hubungan antara proton dan karbon dalam satu ikatan. Sinyal proton yang muncul sebanyak 5 sinyal sehingga dalam spektrum HSQC muncul 5 titik korelasi dengan sinyal karbon dalam satu ikatan. Spektrum HSQC menunjukkan ikatan karbon $\left(\delta_{\mathrm{c}} 103,7 \mathrm{ppm}\right)$ berikatan dengan proton $\left(\delta_{\mathrm{H}} 6,77 \mathrm{ppm}, \mathrm{s}\right)$, karbon $\left(\delta_{\mathrm{c}} 110,0 \mathrm{ppm}\right)$ dengan proton $\left(\delta_{\mathrm{H}}\right.$ $7,16 \mathrm{ppm}, \mathrm{s})$, karbon $\left(\delta_{\mathrm{c}} 113,2 \mathrm{ppm}\right)$ dengan proton $\left(\delta_{\mathrm{H}} 6,15 \mathrm{ppm} ; \mathrm{d} ; \mathrm{J}=9,5\right)$, dan karbon $\left(\delta_{\mathrm{c}} 144,6 \mathrm{ppm}\right)$ dengan proton $\left(\delta_{\mathrm{H}} 7,82 ; \mathrm{d}\right.$; $\mathrm{J}=9,5 \mathrm{~Hz}$ ).

Berdasarkan spektrum HMBC, pada proton $\left(\delta_{\mathrm{H}} 7,16 \mathrm{ppm}, \mathrm{s}\right)$ yang berkorelasi terhadap sinyal karbon dengan pergeseran kimia $\left(\delta_{C} 144,6 ; 151,1 ; 151,9 ;\right.$ dan 146,0 ppm). Proton olefinik pada karbon nomer 3 mempunyai pergeseran kimia $\delta_{\mathrm{H}} 6,15 \mathrm{ppm}$. Proton ini berkolerasi dengan dengan atom $\left(\delta_{\mathrm{C}} 110,0 \mathrm{ppm}\right)$ dan karbon karbonil C2 $\left(\delta_{\mathrm{C}}\right.$ $161,3 \mathrm{ppm})$. Proton doublet $\delta_{\mathrm{H}} 7,82 \mathrm{ppm}$ pada olefinik mengikat pada C4 menunjukkan kontur-kontur yang berkorelasi dengan atom karbon $\left(\delta_{\mathrm{C}} 161,3\right.$ $\mathrm{ppm}),\left(\delta_{\mathrm{C}} 110,0 \mathrm{ppm}\right)$ dan $\left(\delta_{\mathrm{C}} 151,1 \mathrm{ppm}\right)$. Berdasarkan analisis spektrum COSY muncul korelasi antara sinyal proton olefinik dengan pergeseran $\left(\delta_{\mathrm{H}} 6,15\right.$ dan $\left.7,82 \mathrm{ppm}\right)$ yang terikat pada karbon C-3 dan C-4. Korelasi untuk sinyal proton metoksi $\delta_{\mathrm{H}} 3,88$ ppm dengan atom karbon oksiaril pada pergeseran $\delta_{C} 146,0 \mathrm{ppm}$ menunjukkan bahwa atom karbon tersebut merupakan atom karbon C-6. Spektrum NOESY menunjukkan bahwa terdapat korelasi sinyal proton antara $\delta_{\mathrm{H}} 3,88 \mathrm{ppm}$ dengan $\delta_{\mathrm{H}} 7,16$ ppm; $\delta_{\mathrm{H}} 7,82 \mathrm{ppm}$ dengan $\delta_{\mathrm{H}} 7,16 \mathrm{ppm}$; dan $\delta_{\mathrm{H}} 7,82 \mathrm{ppm}$ dengan $\delta_{\mathrm{H}} 6,15 \mathrm{ppm}$. Korelasi antara $\delta_{\mathrm{H}} 3,88 \mathrm{ppm}$ dan $\delta_{\mathrm{H}} 7,16 \mathrm{ppm}$ menunjukkan bahwa atom karbon dengan pergeseran $\delta \mathrm{c} 146,0 \mathrm{ppm}$ terletak pada karbon C-6. Sehingga atom karbon C7 memiliki pergeseran kimia $\delta \mathrm{c} 151,9 \mathrm{ppm}$ dan mengikat gugus hidroksi (Silverstein et al, 2005). Korelasi proton dan karbon berdasarkan spektrum HMBC terdapat pada gambar 1. 


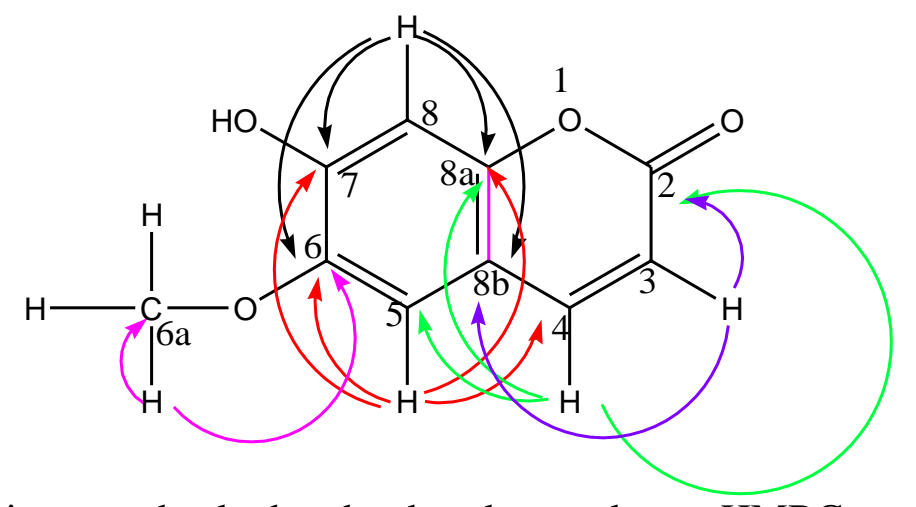

Gambar 1. Korelasi proton dan karbon berdasarkan spektrum HMBC.

Tabel 1. Data spektrum 1D dan 2D NMR senyawa skopoletin

\begin{tabular}{cccc}
$\mathrm{C}$ & $\delta \mathrm{C}$ & $\delta \mathrm{H}(\mathrm{mult}, \mathrm{J}) \mathrm{ppm}$ & $\mathrm{HMBC}$ \\
\hline & & & \\
\hline 2 & 161,3 & - & - \\
3 & 113,2 & $6,15(\mathrm{~d}, \mathrm{~J}=9,5 \mathrm{~Hz})$ & $\mathrm{C}-2, \mathrm{C}-8 \mathrm{~b}$ \\
4 & 144,6 & $7,82(\mathrm{~d}, \mathrm{~J}=9,5 \mathrm{~Hz})$ & $\mathrm{C}-2, \mathrm{C}-5, \mathrm{C}-8 \mathrm{a}$ \\
5 & 110,0 & $7,16(\mathrm{~s})$ & $\mathrm{C}-4, \mathrm{C}-6, \mathrm{C}-7, \mathrm{C}-8 \mathrm{a}$ \\
6 & 146,0 & - & - \\
$6 \mathrm{a}$ & 56,7 & $3,88(\mathrm{~s})$ & $\mathrm{C}-4$ \\
7 & 151,9 & - & - \\
8 & 103,7 & $6,77(\mathrm{~s})$ & $\mathrm{C}-6, \mathrm{C}-7, \mathrm{C}-8 \mathrm{a}, \mathrm{C}-8 \mathrm{~b}$ \\
$8 \mathrm{a}$ & 151,1 & - & - \\
$8 \mathrm{~b}$ & 112,0 & - & -
\end{tabular}

Berdasarkan data HMBC, HSQC, COSY, dan NOESY tersebut maka struktur senyawa golongan fenilpropanoid yang berhasil diisolasi adalah 7-hidroksi-6-metoksikroman-2-on yang dikenal dengan nama skopoletin (Forino et al, 2016). Analisis data NMR untuk senyawa skopoletin menunjukkan gambar struktur senyawa skopoletin pada gambar 2 . 


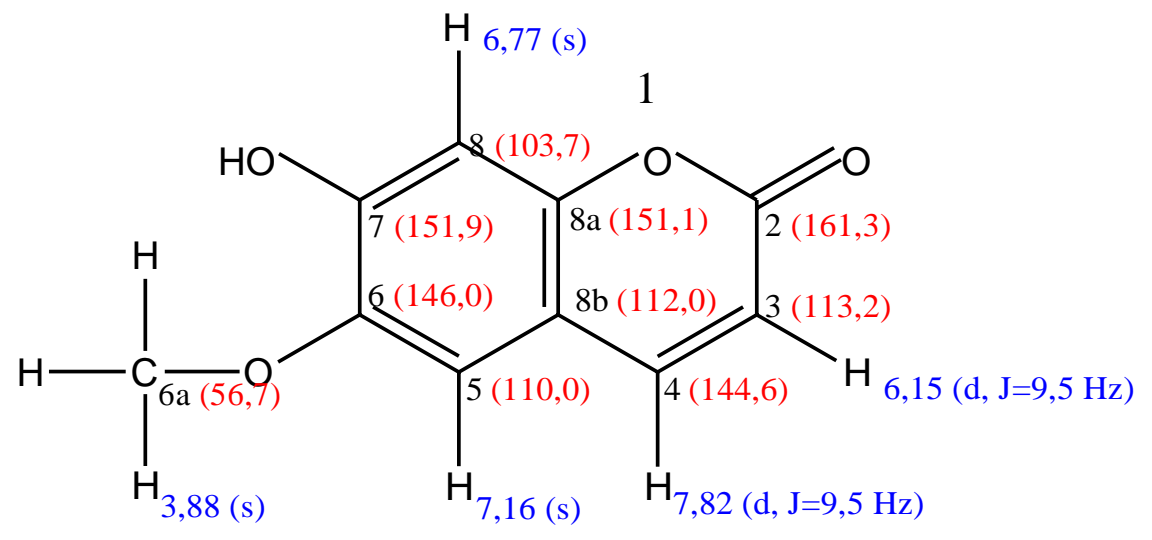

Gambar 2. Struktur senyawa skopoletin dengan pergeseran kimia proton dan karbon $\left(\right.$ merah $=\delta_{\mathrm{C}}(\mathrm{ppm})$ dan biru $\left.=\delta_{\mathrm{H}}(\mathrm{ppm})\right)$.

Berdasarkan jurnal Forino et al, (2015) spektrum ${ }^{1} \mathrm{H}-\mathrm{NMR}$ dan ${ }^{13} \mathrm{C}-\mathrm{NMR}$ dari skopoletin hasil isolasi dengan jurnal ini nilai pergeseran kimianya hampir sama. Pada jurnal ini juga menunjukkan skopoletin yang diperoleh mempunyai struktur seperti gambar 2. Perbandingan pergeseran kimia sinyal karbon dan proton dengan jurnal dari senyawa skopoletin terdapat pada tabel 2 .

Tabel 2. Pergeseran kimia skopoletin dibandingkan dengan data NMR dari jurnal Forino et al, (2015)

\begin{tabular}{|c|c|c|c|c|}
\hline $\mathrm{C}$ & $\begin{array}{c}\delta \mathrm{C} \\
\text { senyawa } 1 \\
\end{array}$ & $\begin{array}{c}\delta \mathrm{H}(\text { mult, } \mathrm{J}) \mathrm{ppm} \\
\text { senyawa } 1\end{array}$ & $\begin{array}{c}\delta \mathrm{C} \text { ppm } \\
\text { (Forino et al, 2015) }\end{array}$ & $\begin{array}{c}\delta \mathrm{H} \text { ppm } \\
\text { (Forino et al, 2015) }\end{array}$ \\
\hline 2 & 161,3 & - & 164,2 & - \\
\hline 3 & 113,2 & $6,15(\mathrm{~d}, \mathrm{~J}=9,5 \mathrm{~Hz})$ & 112,8 & 6,18 \\
\hline 4 & 144,6 & $7,82(\mathrm{~d}, \mathrm{~J}=9,5 \mathrm{~Hz})$ & 146,3 & 7,84 \\
\hline 5 & 110,0 & $7,16(\mathrm{~s})$ & 110,2 & 7,10 \\
\hline 6 & 146,0 & - & 147,2 & - \\
\hline $6 a$ & 56,7 & $3,88(\mathrm{~s})$ & 56,9 & 3,88 \\
\hline 7 & 151,9 & - & 153,1 & - \\
\hline 8 & 103,7 & $6,77(s)$ & 104,1 & 6,75 \\
\hline $8 a$ & 151,1 & - & 151,6 & - \\
\hline $8 b$ & 112,0 & - & 112,7 & - \\
\hline
\end{tabular}

Jadi, identifikasi senyawa 1 dengan analisis UV, 1D, dan 2D NMR menunjukkan bahwa senyawa 1 merupakan senyawa turunan kumarin yaitu skopoletin (7hidroksi-6-metoksi-kroman-2-on).

\section{Kesimpulan}

Senyawa golongan fenilpropanoid telah berhasil diisolasi dari ekstrak etil asetat umbi ubi jalar (Ipomoea batatas L.) dan diidentifikasi dengan spektrum UV, 1D dan 2D NMR sebagai skopoletin (7-hidroksi-6metoksi-kroman-2-on). 


\section{Daftar Pustaka}

Ariadi, Y., B., 2006, Perbandingan Berbagai

Varietas Ubi Jalar Ditinjau Dari

Pendapatan Usahatani dan Pemasaran

Di Kabupaten Malang Comparison

Among Various Sweet Potato Varieties

Focused From Farm Income Dan

Marketing At Malang Regency, Jurnal

Pembangunan Pedesaan, 6 (2), 14119250

Forino, M., Luciana, T., Dell'Averssana, C., Ciminielo, 2015, O., NMRBased Identification of The Phenolic Profile of Fruits Of Lycium Barbarum (Goji Berries). Isolation and Structural Determination Of A Novel N-Feruloyl Tyramine Dimer As The Most Abundant Antioxidant Polyphenol Of Goji Berries, Elsevier, 194, 1254-1259.

Meira, M., Da Silva, E. P., David, J. M., David, J. P., 2012, Review of the genus Ipomoea: traditional uses, chemistry dan biological activities, Revita Brasileira, 22 (3), 682-71

Scott, A. I., 1964, Interpretation of The Ultraviolet Spectra of Natural Product, Pergamon Press Ltd : Oxford.

Silverstein, R.M., Webster, F.X., Kiemle, D.J., 2005, Spectrometric Identification of organic Compound, $7^{\text {th }}$ Edittion, John Willey \& Sons Ltd : United States. 